\title{
Biological Properties of Silver Nanoparticles from $\beta$ (1-3) Glucan Isolated from the Edible Mushroom Pleurotus florida
}

\author{
Meera C Radhakrishnan 1,*iD, Nisha Peter ${ }^{1}$ \\ 1 Department of Microbiology, St Mary's College, Thrissur-680020, Kerala, India \\ * Correspondence: meeramaheswaran2005@gmail.com;
}

Scopus Author ID 15923272600

Received: 12.07.2020; Revised: 7.10.2020; Accepted: 10.10.2020; Published: 17.10.2020

\begin{abstract}
Pleurotus florida of the genus Pleurotus is a delicious edible mushroom with high therapeutic potential. Silver nanoparticles (AgNPs) are gaining a lot of importance nowadays because of their wide industrial and biomedical applications. Capping of AgNPs with polysaccharides, the most potent mushroom derived metabolites, is promising towards natural drug development for free radical-induced ailments. In the present investigation, silver nanoparticles were synthesized using $\beta$-glucan isolated from P. florida, and their antioxidant properties were studied. Polysaccharide (PS) isolation was carried out by hot water extraction, alcohol precipitation, deproteinization, and dialysis. Preliminary characterization of PS by Anthrone, Lowry's method, Paper Chromatography, and FT-IR showed that PS is protein-bound $\beta-(1-3)$ - Glucan. Synthesis of Silver nanoparticle from PS (PS-AgNPs) was confirmed by UV spectroscopy. Antioxidant properties of PS and PS-AgNPs were evaluated by Total antioxidant capacity assay, DPPH assay, Total reducing power, and Hydroxyl radical scavenging assay. Both PS and PS-AgNPs showed profound antioxidant activity in a dose-dependent manner, and PSAgNPs was more active than PS. The highest activity was shown in Hydroxyl radical scavenging assay in which PS and PS-AgNPs showed $81.8 \%$ and $89.4 \%$ activity, respectively, at the highest tested dose. The present study revealed the possible use of $P$. florida in antioxidant drug development.
\end{abstract}

Keywords: Pleurotus florida; edible mushroom; $\beta$-glucans; Silver nanoparticles; antioxidant activity; free radicals.

(C) 2020 by the authors. This article is an open-access article distributed under the terms and conditions of the Creative Commons Attribution (CC BY) license (https://creativecommons.org/licenses/by/4.0/).

\section{Introduction}

Mushrooms represent a major and yet largely untapped source of powerful new pharmaceutical products [1]. Chang and Miles coined the term 'mushroom' and defined them as 'macro fungus with a distinctive fruiting body, large enough to be seen with the naked eye and to be picked by hand, which can be either hypogeous or epigeous [2]. Mushrooms have been part of human diet and folk medicine since ancient history because of their abundance in nutritional components [3], multiple pharmaceutical properties [4], excellent sensory characteristics [5], and ease in the management and cultivation techniques [6]. Initially, mushrooms were popular as food, and ancient Egyptians and ancient Chinese used them as health boosters and also for longevity. Later their medicinal properties were identified, and the pharmaceutical potential of mushrooms has become a hot spot of research for the last two decades. It is assumed that the number of mushrooms identified to date forms only $10 \%$ of the total mushrooms that exist in nature [7]. 
Mushrooms are rich in bioactive metabolites and are considered as a safe source for natural drugs with the least or no toxicity. The biological properties of mushrooms are fascinating and are known to possess a wide array of activities, including antioxidant, antihypertensive, hypocholesterolemic, liver protection, anti-inflammatory, anti-diabetic, antiviral, and antimicrobial [8]. The bioactive metabolites isolated and identified from mushrooms include polysaccharides [9,10], proteins [11], glycoproteins [12], unsaturated fatty acids [13], phenolic compounds [14], tocopherols [15], ergosterols [16], lectins [17] etc. Polysaccharides are the most promising and well-known mushroom derived compounds and include mainly the polysaccharides, in particular $\beta$-D-glucans, polysaccharo-peptides (PSP) as well as polysaccharide-protein complexes. $\beta$-glucans possess significant medicinal properties like immunomodulation, antimicrobial, antioxidant, antiviral, antifungal, antitumor, cholesterollowering, and blood glucose regulation activities [18].

Pleurotus species belong to the phylum Basidiomycota, and they produce characteristic oyster shaped fruiting bodies or basidiocarps, hence called Oyster Mushroom (OM). These saprophytic fungi enjoy worldwide distribution, grow well in temperate to tropical regions at a temperature range between $12-32^{\circ} \mathrm{C}$ [19], and ranks second in most cultivated edible mushroom in the world. Pleurotus florida of the genus Pleurotus is a delicious edible mushroom with high therapeutic potential, which is widely cultivated on a commercial basis in many parts of the world, including India. Pleuran is the best-known $\beta$-glucan isolated from oyster mushrooms and is consisting of D-glucose molecules with $\beta$ - $(1 \rightarrow 3)$ and $\beta$ - $(1 \rightarrow 6)$ linkages [20]. The compound exhibits strong immunostimulatory activity, anti-cancer properties against various cancer cell lines, including colorectal cancer cells HT-29 [21], prostate cancer cells PC-3 [22], breast cancer cells MCF-7 [23], etc. and are also known to possess antioxidant and antiviral properties [24].

Nanotechnology is an emerging and fast-growing area of modern science due to its promising medical and industrial applications. Their importance in the medical field is due to their variable size, shape, chemical composition, and controlled disparity and due to their potential use for human benefits. The nanoparticles from noble metals like $\mathrm{Ag}, \mathrm{Au}, \mathrm{Pt}$, and $\mathrm{Pd}$ are the most extensively researched ones, and among them, silver nanoparticles were much praised because of their significant application in biomedicine [25]. Some of the mushrooms, including Volvarella volvacea, Pleurotus sajor-caju, Pleurotus florida, and Ganoderma lucidum have been used for the synthesis of AgNPs [26, 27, 28, 29]. The use of natural polysaccharides as stabilizing and reducing agents in the green synthesis of metallic nanoparticles (MNPs) has become a promising area in nanotechnology because of their excellent properties owing to chemical and structural diversity [30, 31,32]. The differences ranging in charge, chain lengths, monosaccharide sequences, and stereochemistry give them the highest capacity for the development of advanced functional materials and biomedicine [33].

Free radicals are continuously generated in our body due to many reasons, which include exposure to sunlight, ultraviolet light, and ionizing radiation, as well as chemical reactions and metabolic processes. These generated free radicals adversely affect the biomolecules in the human body and are known to involve in the pathophysiology of numerous diseases, including atherosclerosis, carcinogenesis, neurodegenerative ailments, chronic inflammation, radiation-induced damage, aging, and various other pathological conditions [34, 35]. Polysaccharides, which are the major constituents of mushrooms, have been demonstrated to play an important role as a dietary free-radical scavenger for the prevention of 
oxidative damage. However, the effectiveness of natural sources has a poor rate of absorption, difficulties in transportation across cell membranes, and undergo degradation during delivery, which all limit their bioavailability. Capping of natural antioxidants with nanoparticles stability, biocompatibility, targeted delivery, as well as their slow and sustained release [36].

The present investigation was focused on the isolation and preliminary characterization of polysaccharides (PS) from the basidiocarps of the edible mushroom Pleurotus floria. The study was also focused on the biosynthesis of silver nanoparticles (AgNPs) with the isolated PS and estimation of the antioxidant potential of both the PS and the synthesized PS based AgNPs.

\section{Materials and Methods}

\subsection{Isolation of polysaccharide (PS) from Pleurotus florida.}

Fruiting bodies of Pleurotus florida were purchased from Kerala Agriculture University, Mannuthy, Thrissur, Kerala, India. Saprocarps were washed thoroughly, cut into small pieces, dried at $40-50^{\circ} \mathrm{C}$ for 48 hours, and powdered. Then the powdered material was defatted in the Soxhlet apparatus using petroleum ether as a solvent for 8-10 hrs. This defatted material was subjected to hot water extraction at $80-90^{\circ} \mathrm{C}$ for $8-9 \mathrm{hrs}$, and the extraction was repeated thrice. After each extraction, the soluble polymers were separated from residues by filtration, pooled together, and concentrated under reduced pressure.

The isolation of polysaccharide from Pleurotus florida was carried out by the method of Mizuno [37] with slight modifications. Briefly, precipitated the hot water extract with $3 \mathrm{X}$ volume of chilled ethanol, kept at $4^{\circ} \mathrm{c}$ for $48 \mathrm{hrs}$, followed by centrifugation at $10000 \mathrm{rpm}$ for 20min. The precipitate obtained was deproteinized with the Sevag method [38] and again precipitated with chilled ethanol. The obtained precipitate was dialyzed against distilled water for 3 days and lyophilized to get the PS.

\subsection{Characterization of PS isolated from Pleurotus florida.}

Qualitative and quantitative estimation of carbohydrate was carried out by the Anthrone method [39]. Glucose was used as the standard. To detect the monosaccharide profile, 10mg of PS was hydrolyzed with $3 \mathrm{ml}$ of concentrated Sulphuric acid and then neutralized with Sodium carbonate to achieve saturation. The residue obtained after hydrolysis was dissolved in $10 \%$ isopropanol and analyzed by paper chromatography using Whatman No 1 filter paper. The chromatograms were developed with butanol: acetic acid: water (2:1:1) solvent system. After development, the plates were dried in air and sprayed with the aniline diphenylamine phosphoric acid prepared in acetone and then heated at $85^{\circ} \mathrm{c}$ for $10 \mathrm{~min}$. Glucose, fructose, and sucrose were used as standard. For further characterization of isolated PS, Fourier transformed infrared spectroscopy (FT-IR) was carried out. PerkinElmer Spectrum version 10.3.6. was used for FT-IR analysis. Total protein content was estimated by Lowry's method [40]. g Bovine serum albumin (BSA) was used as the standard.

\subsection{Biosynthesis of silver nanoparticles.}

The PS isolated from $P$. florida was mixed with $\mathrm{AgNO}_{3}$ solution $(0.001 \mathrm{M})$ maintained at room temperature for $48 \mathrm{hrs}$ for the complete conversion of $\mathrm{AgNO}_{3}$ to $\mathrm{AgNPs}_{\text {. Control (PS }}$ 
without $\mathrm{AgNO}_{3}$ ) was also kept. The samples were subjected to UV analysis in the wavelength ranging from 200 to $500 \mathrm{~nm}$ using UV Spectrophotometer to confirm the formation of AgNPs.

\subsection{Antioxidant activity.}

\subsubsection{Total antioxidant capacity assay (TACA).}

The total antioxidant capacity was measured according to spectrometric methods of Pretio et al. [41]. Various concentrations of PS and PS - AgNPs were combined with $1 \mathrm{ml}$ of reagent solution $(0.6 \mathrm{M}$ sulphuric acid, $2.8 \mathrm{mM}$ sodium phosphate, and $4 \mathrm{mM}$ ammonium molybedate) and incubated at $95^{\circ} \mathrm{c}$ for 90 minutes. After cooling to room temperature, the absorbance was measured at $695 \mathrm{~nm}$ against blank. The percent activity of treatment against control was calculated by the formula:

$$
\% \text { activity }=\mathrm{T}-\mathrm{C} / \mathrm{T}
$$

Where $\mathrm{C}=$ absorbance of the control and $\mathrm{T}=$ absorbance of treated.

\subsubsection{DPPH-Free radical scavenging assay.}

In this method, commercially available and stable free radical 2,2- diphenyl 1-1picrylhydrazil(DPPH+) soluble in ethanol was used [42]. DPPH, in its radical form, has an absorption peak at $515 \mathrm{~nm}$, which disappeared on reduction by an antioxidant compound. Aliquots of different concentrations of PS and PS- AgNPs were added to $1 \mathrm{ml}$ of freshly prepared DPPH solution $(0.25 \mathrm{~g} / 1$ in ethanol). The samples were kept for $20 \mathrm{~min}$ in darkness before measuring optical density at $515 \mathrm{~nm}$.

Given formula was used to calculate the free radical scavenging activity:

$$
\% \text { activity }=\mathrm{C}-\mathrm{T} / \mathrm{C}
$$

Where $\mathrm{C}=$ absorbance of the control and $\mathrm{T}=$ absorbance of treated.

\subsubsection{Total reducing power assay.}

Different concentrations of PS and PS- AgNPs were mixed with $2.5 \mathrm{ml}$ of phosphate buffer $(200 \mathrm{~mm}, \mathrm{pH} 6.6)$ and $1 \%$ potassium ferricyanide $(205 \mathrm{ml})$. The mixtures were incubated for $20 \mathrm{in}$ at $50^{\circ} \mathrm{c}$. After incubation, $2.5 \mathrm{ml}$ of $10 \%$ trichloroacetic acid was added to the mixtures, followed by centrifugation for $10 \mathrm{~min}$. The upper layer $(5 \mathrm{ml})$ was mixed with $5 \mathrm{ml}$ of distilled water and $1 \mathrm{ml}$ of $0.1 \%$ ferric chloride, and the absorbance of the resultant solution was measured at $700 \mathrm{~nm}$.

The reducing activity was calculated by the formula:

$$
\% \text { activity }=\mathrm{T}-\mathrm{C} / \mathrm{T}
$$

Where $\mathrm{C}=$ absorbance of the control and $\mathrm{T}=$ absorbance of treated.

\subsubsection{Hydroxyl radical scavenging assay.}

In Hydroxyl radical scavenging assay, hydroxyl radicals, generated by the reaction of an iron-EDTA complex with $\mathrm{H}_{2} \mathrm{O}_{2}$ in the presence of ascorbic acid, attack deoxyribose to form products (Malondialdehyde) that, upon heating with thiobarbituric acid at low $\mathrm{pH}$, yield a pink chromogen. Added hydroxyl radical scavengers compete with deoxyribose for the hydroxyl radicals and thus inhibit the formation of chromogen. The assay was performed by adding 0.1 $\mathrm{ml}$ of the reaction mixture (Ferric chloride, ascorbic acid, EDTA, and phosphate buffer), 0.1 $\mathrm{ml}$ of $\mathrm{H}_{2} \mathrm{O}_{2}$, and $0.1 \mathrm{ml}$ of deoxyribose. Distilled water was used to make up the reaction 
mixture to $1 \mathrm{ml}$. $0.1 \mathrm{ml}$ of PS and PS - AgNPs were added to it and incubated for 1 hour. $1 \mathrm{ml}$ TBA was added to the incubated mixture to develop pink chromogen and absorbance was measured at $532 \mathrm{~nm}$.

The capability to scavenge the hydroxyl radical was calculated using the formula:

$$
\% \text { of activity }=\mathrm{C}-\mathrm{T} / \mathrm{C}
$$

Where $\mathrm{C}=$ absorbance of the control and $\mathrm{T}=$ absorbance of treated.

\subsubsection{Statistical analysis.}

All antioxidant experiments were conducted in triplicates, and experimental data were expressed as mean \pm standard deviation.

\section{Results and Discussion}

The polysaccharide from the fruiting body of Pleurotus florida was isolated by hot water extraction, filtration, chilled ethanol precipitation, and centrifugation. The received material was deproteinized by the Sevag method. Thus obtained PS was subjected to dialysis, followed by lyophilization. The yield of PS was found to be $3.85 \%$.

\subsection{Characterization of PS isolated from Pleurotus florida.}

Quantitative, as well as qualitative estimation of carbohydrate in PS, was done by the Anthrone method, and PS showed the presence of 52\% carbohydrate. The monosaccharide profile of isolated PS was done by paper chromatography. The Rf value of PS was found to be closer to that of glucose used as standard. No other spots were developed on chromatograms from PS, which indicated that the only monomer present is glucose (Figure 1).

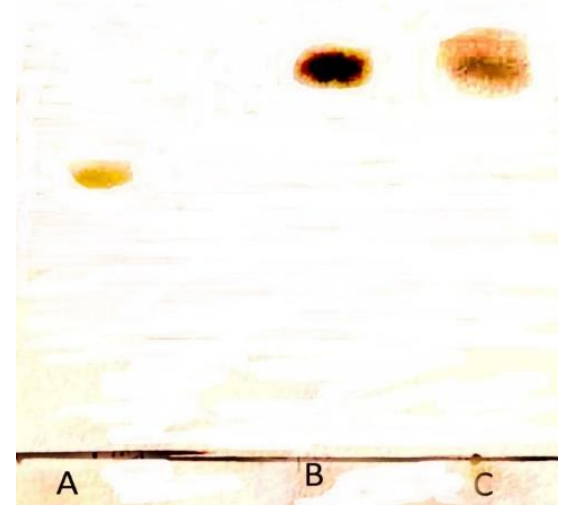

Figure 1. Paper chromatographic pattern of monomers from PS of P.florida using Whatman No:1 filter paper. Solvent system-butanol: acetic acid: water (2: 1: 1), Spray reagent-Aniline diphenylamine phosphoric acid reagent. Spot (A) and (B) are Fructose and Glucose used as standards; Spot (C) is PS from P.florida.

In order to determine the functional groups of the purified PS, the FT-IR spectra were measured in $\mathrm{KBr}$ pellets. The spectrum of FT-IR is shown in Figure 2. According to literature, a peak at 1217.8 can be attributed to $\beta$-D Glucan [43]. The absorption peak at $1069 \mathrm{~cm}-1$ was characteristic of the presence of $\beta$ (1-3) Glucan Absorption at 1069.93 also indicated a pyranose form of the glycosyl residue [44]. The band corresponding to the $v(C=O)$ vibration in the carboxyl group at $1569.83 \mathrm{~cm}^{-1}$ indicates that this carbonyl group was hydrogen-bonded 
and also indicated the presence of residual protein attached to PS from P.florida [43] (Figure 2). Furthermore, the banding like structure in the region of $2923.67 \mathrm{~cm}^{-1}$ as well as a continuous absorption beginning at approximately the region of $3397.56 \mathrm{~cm}^{-1}$ is characteristic of a carbohydrate ring. Thus, the results indicated that PS isolated from P.florida consisted of cyclic glucose with $\beta$ glycosidic bonds, i.e., $\beta$-glucopyranose with $\beta$ (1-3) linkage.

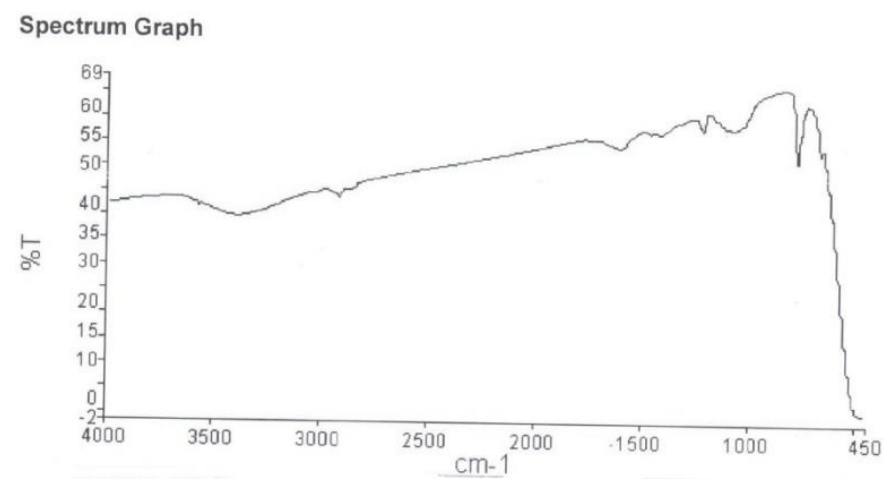

Figure 2. FT-IR spectrum of PS isolated from P.florida.

Estimation of protein in PS by Lowry's method showed the presence of $13.2 \%$ Protein. Sevag method usually removes unbound proteins, and proteins that are bound to the polysaccharides are not easily removed by this method. The presence of protein even after the Sevag method revealed the protein-bound nature of PS. FT-IR results also confirmed that the PS is protein bound. Thus the preliminary characterization showed that the PS isolated from $P$. florida is a protein-bound $\beta$ (1-3) Glucan. Further structural analysis is required to elucidate the detailed structure and branching of this molecule.

\subsection{Biosynthesis of silver nanoparticles.}

AgNPs have enormous applications in the medical field due to their profound features. Green synthesis of AgNPs using non-toxic and naturally occurring capping agents are shown to possess strong antioxidant potential [36]. The synthesis of AgNPs was observed when PS was incubated with silver nitrate. The silver nitrate treated with PS turned brown in color, whereas the control without $\mathrm{AgNO}_{3}$ showed no color change. Colour change is considered an indication of AgNPs formation (Figure 3).

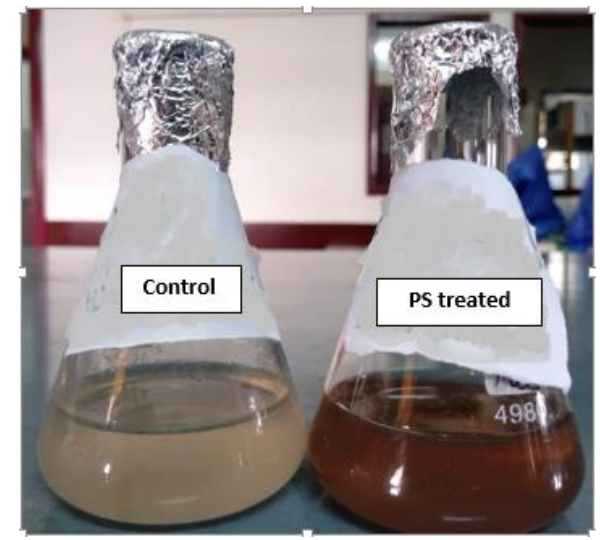

Figure 3. PS treated with or without Silver nitrate. PS without $\mathrm{AgNO}_{3}$ showed no color change whereas treated one turned brown in color. 
The color change could be due to the formation of silver nanoparticles of varying shape and size and can be attributed to the excitation of surface plasmon resonance (SPR) peaks of the Nobel metal nanoparticles [45]. The formatiojn of AgNPs was further confirmed by UV spectroscopy. From the UV Spectroscopy analysis, it was found that PS showed an absorbance peak in the visible region at $240 \mathrm{~nm}$. Characteristic peaks in the range of 200-500 nm are considered as clear evidence for the formation of NPs [46]. Results thus indicated that PS from $P$. florida mushroom enhanced the reduction of silver nitrate to silver nanoparticles.

\subsection{Antioxidant activity of PS and PS-AgNPs.}

Antioxidant potential of both PS and AgNPs synthesized from PS (PS-AgNPs) were analyzed by Total antioxidant capacity assay, DPPH-Free radical scavenging assay, Total reducing power assay, and Hydroxyl radical scavenging assay. In all antioxidant assays, both PS and PS-AgNPs from P.florida showed significant activity in a dose-dependent manner. In all assays, silver nanoparticles were found to potentiate the antioxidant activity of PS.

In the total antioxidant capacity assay, PS showed $80.5 \%$ activity, and PS-AgNPs showed an activity of $82.55 \%$ at the highest tested concentration of $2000 \mu$ g (Figure 4). In DPPH assay, PS and PS-AgNPs showed an activity of $69.9 \%$ and $75.6 \%$, respectively, at the highest tested dose. In DPPH assay also, there was a considerable increase in the activity of silver nanoparticle capped PS than PS alone (Figure 5). In the Total reducing power assay, PS showed $84.35 \%$ activity, and PS-AgNPs showed an activity $87.1 \%$ at the highest tested concentration, and there was an enhancement by $2.75 \%$ in the activity of PS by AgNPs formation (Figure 6). Among all antioxidant assays conducted, Hydroxyl radical scavenging activity was most enhanced by Silver nanoparticle synthesis. The silver nanoparticle enhanced the hydroxyl radical scavenging activity of PS by 7.6\% (Figure 7).

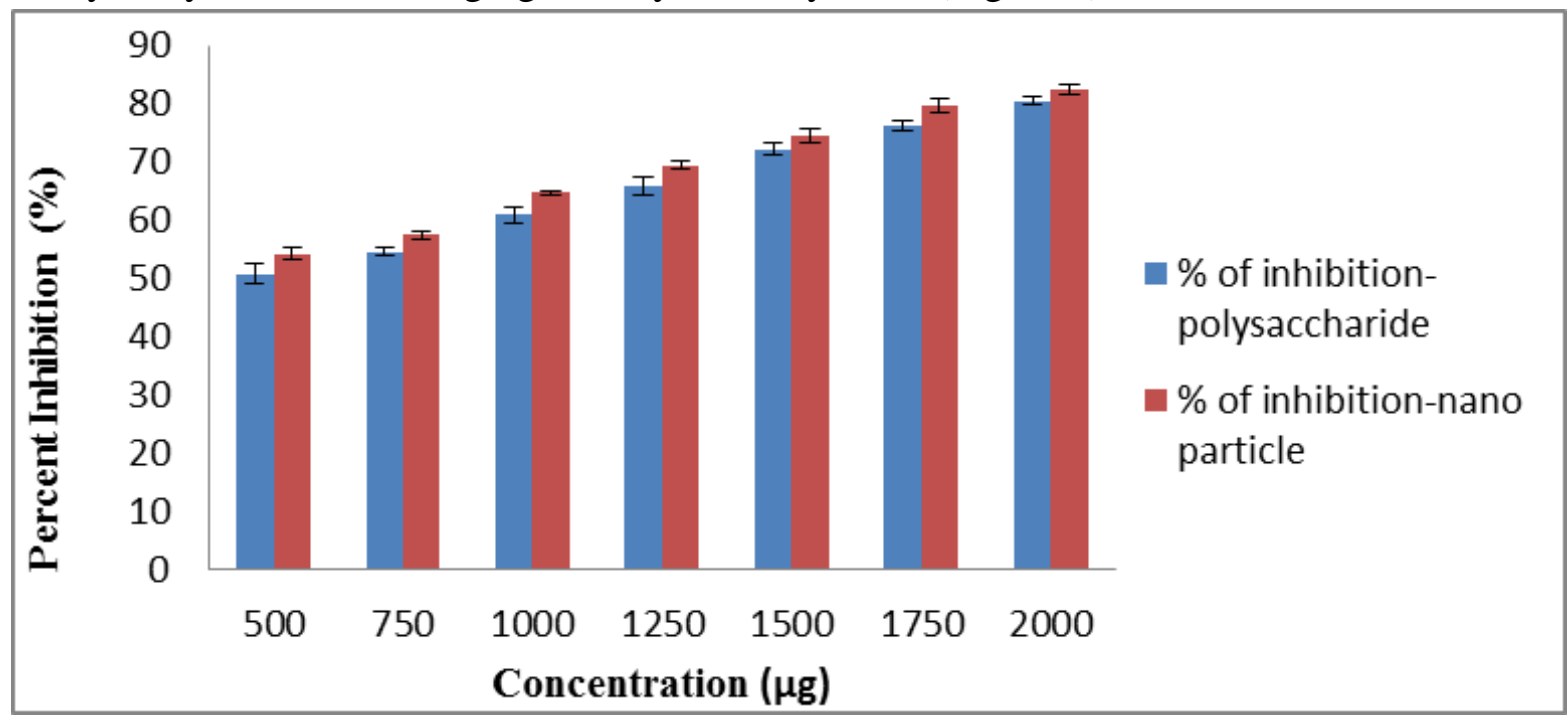

Figure 4. Total antioxidant capacity assay of PS and PS-AgNPs from P.florida. Values are mean $\pm \mathrm{SD}, \mathrm{n}=3$.

The association of the protein with the polysaccharide molecules is known to potentiate their free radical scavenging activity [47]. The protein-bound nature of PS may be responsible for its high antioxidant property. Capping of AgNPs with non-toxic agents from natural resources is known to mask the toxic effects of silver nanoparticles and are known to have free radical scavenging potential [36]. Nanoparticles have several added advantages over traditional antioxidant delivery methods, which include environmental protection of bioactive components, increased bioavailability, and targeted delivery of antioxidants, as well as a 
controlled release at the site of action [48]. Capping of silver nanoparticles with PS might have improved the bioavailability, delivery, and release of PS and thus enhanced the antioxidant potential of PS-AgNPs compared to PS.

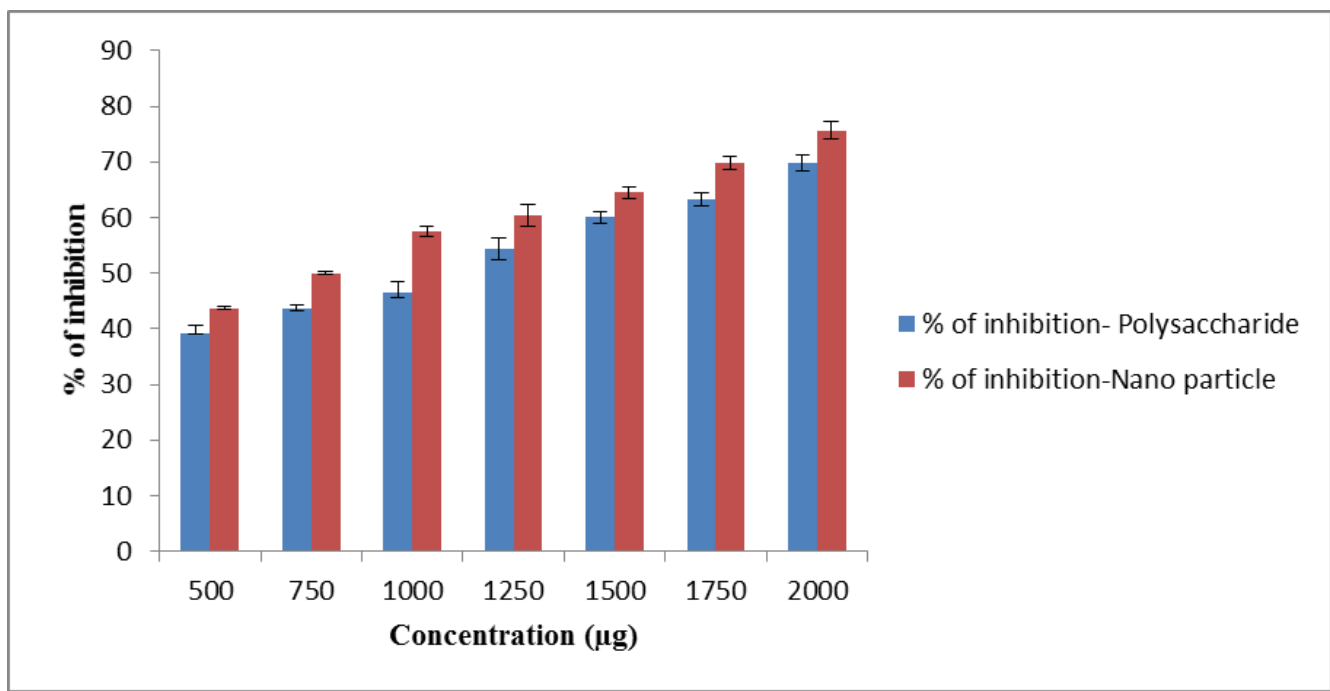

Figure 5. DPPH Free radical scavenging activity of PS and PS-AgNPs from P.florida. Values are mean \pm SD, $\mathrm{n}=3$.

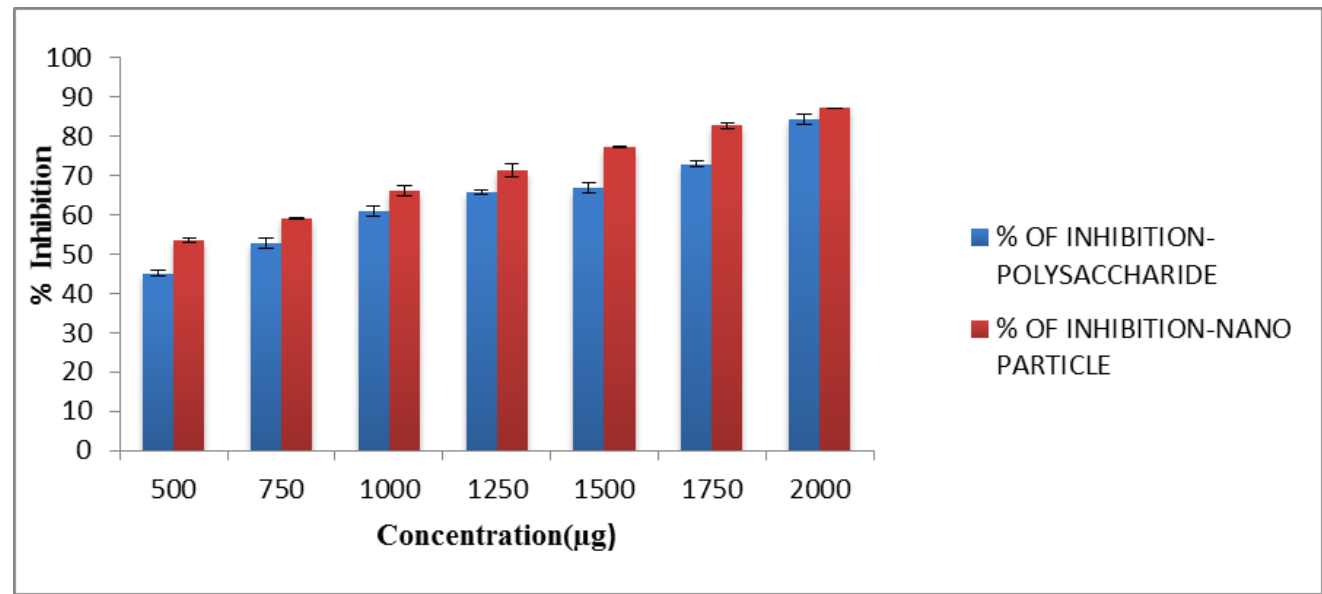

Figure 6. Total reducing power assay of PS and PS-AgNPs from P.florida. Values are mean $\pm \mathrm{SD}, \mathrm{n}=3$.

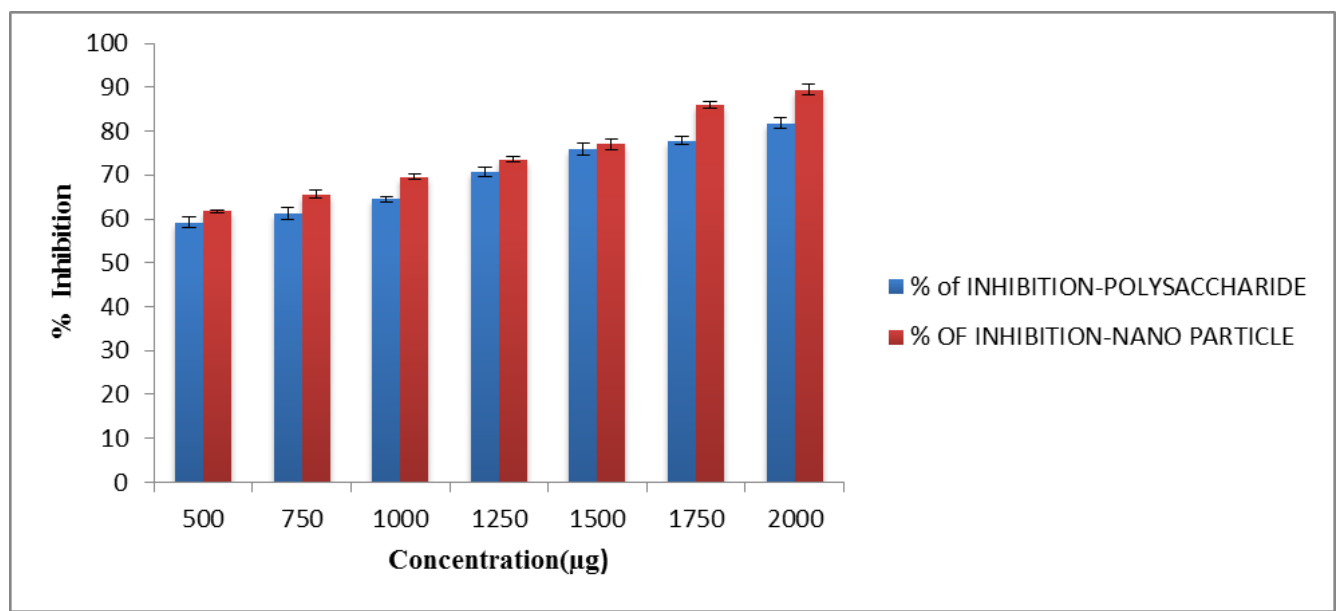

Figure 7. Hydroxyl radical scavenging activity of PS and PS-AgNPs from P.florida. Values are mean \pm SD, $\mathrm{n}=3$. 


\section{Conclusions}

The present investigation revealed that the PS isolated from P.florida is protein-bound $\beta$ (1-3) Glucan. AgNPs were synthesized using $\beta$ (1-3) Glucan of P.florida. Isolation of $\beta$ Glucan, as well as biosynthesis of silver nanoparticles using $P$. florida is simple, cost-effective, and can be carried out with minimal effort. Both the PS and PS-AgNPs of P.florida showed significant antioxidant activity in a dose-dependent manner. Thus, the study revealed that both the PS and PS-AgNPs synthesized from the edible mushroom P.florida could serve as a suitable candidate for antioxidant drug development from natural sources.

\section{Funding}

This research received no external funding.

\section{Acknowledgments}

The authors are thankful to St Mary's College, Thrissur-680020, Kerala, India.

\section{Conflicts of Interest}

The authors declare no conflict of interest.

\section{References}

1. Wasser, S.P. Medicinal mushrooms as a source of antitumour and immunomodulating polysaccharides. Appl Microbiol Biotechnol 2002, 60, 258-274, https://doi.org/10.1007/s00253-002-1076-7.

2. Chang, S.T.; Miles P.G. Mushrooms biology-a new discipline. Mycologist 1992, 6, 64-65, https://doi.org/10.1016/S0269-915X(09)80449-7.

3. Kalac, P. Edible Mushrooms: Chemical Composition and Nutritional Value. $1^{\text {st }}$ ed.; Academic Press: San Diego, USA, 2016; pp. 137-153, https://doi.org/10.1016/C2015-0-00471-3

4. Muszyńska, B.; Grzywacz-Kisielewska, A.; Kała, K.; Gdula-Argasińska, J. Anti-inflammatory properties of edible mushrooms: A review. Food Chem. 2018, 243, 373-381, https://doi.org/10.1016/j.foodchem.2017.09.149.

5. Phat, C.; Moon, B.; Lee, C. Evaluation of umami taste in mushroom extracts bychemical analysis, sensory evaluation, and an electronic tongue system. Food Chem 2016, 192, 1068-1077, https://doi.org/10.1016/j.foodchem.2015.07.113.

6. Roncero-Ramos, I.; Delgado-Andrade, C. The beneficial role of edible mushrooms in human health. Curr. Opin. Food Sci. 2017, 14, 122-128, https://doi.org/10.1016/j.cofs.2017.04.002.

7. Abugri, D.; McElhenney, W.H.; Willian, K.R. Fatty acid profiling in selected cultivated edible and wild medicinal mushrooms in the Southern United States. J. Exp. Food Chem. 2016, 2, 1-7.

8. Sharma, D.; Singh, V.P.; Singh, N.K. A Review on Phytochemistry and Pharmacology of Medicinal as well as Poisonous Mushrooms. Mini Rev Med Chem. 2018, 18, 1095-1109, https://doi.org/10.2174/1389557517666170927144119.

9. Ruthes, A.C.; Smiderle, F.R.; Iacomini, M. Mushroom heteropolysaccharides: a review on their sources, structure and biological effects. Carbohydr. Polym. 2016, 136, 358-375. https://doi.org/10.1016/j.carbpol.2015.08.061.

10. Cheung, P.C. Mini-review on edible mushrooms as source of dietary fiber: preparation and health benefits, Food. Sci. Hum. Welln. 2013, 2, 162-166, https://doi.org/10.1016/j.fshw.2013.08.001.

11. El Enshasy, H.A.; Hatti-Kaul, R. Mushroom immunomodulators: unique molecules with unlimited applications. Trends Biotechnol. 2013, 31(12), 668-677. https://doi.org/ 10.1016/j.tibtech.2013.09.003

12. Kumar, K. Role of edible mushrooms as functional foods-a review. South Asian J. Food Technol. Environ. 2015, 1, 211-218.

13. Tel Çayan, G.; Öztürk, M.; Duru, M.; Turkoglu, A. Fatty Acid Profiles in Wild Mushroom Species from Anatolia. Chem. Nat. Compd. 2017, 53, 351-353, https://doi.org/10.1007/s10600-017-1986-3.

14. Heleno, S.A.; Martins, A.; Queiroz, M.J.; Ferreira, I.C. Bioactivity of phenolic acids: metabolites versus parent compounds: a review. Food Chem. 2015, 173, 501-513, https://doi.org/10.1016/j.foodchem.2014.10.057. 
15. Khatua, S.; Paul, S.; Acharya, K. Mushroom as the potential source of new generation of antioxidant: a review. Res. J. Pharm. Technol. 2013, 6, 496-505.

16. Barreira, J.C.M.; Oliveira, M.B.P.P.; Ferreira, I.C.F.R. Development of a Novel Methodology for the Analysis of Ergosterol in Mushrooms. Food Anal. Methods 2014, 7, 217-223. https://doi.org/10.1007/s12161-013-9621-9

17. Singh S.S.; Wang. H.; Chan. Y.S.; Pan. W.; Dan. X.; Yin. C.M.; Akkouh. O.; Ng. T.B. Lectins from Edible Mushrooms. Molecules. 2014, 20, 446-469, https://doi.org/10.3390/molecules20010446.

18. Vetvicka, V.; Vannucci, L.; Sima, P.; Richter, J. Beta Glucan: Supplement or Drug? From Laboratory to Clinical Trials. Molecules. 2019, 24, https://doi.org/10.3390/molecules24071251.

19. Bellettini, M.B.; Fiorda, F.A.; Maieves, H.A.; Teixeira, G.L.; Ávila, S.; Hornung, P.S.; Júnior, A.M.; Ribani, R.H. Factors affecting mushroom Pleurotus spp. Saudi J Biol Sci. 2019, 26, 633-646. https://doi.org/10.1016/j.sjbs.2016.12.005.

20. Maftoun P.; Malek, R.; Abdel-Sadek, M.; Aziz R.; El Enshasy H. Bioprocess for semi-industrial production of immunomodulator polysaccharide Pleuran by Pleurotus ostreatus in submerged culture. J. Sci. Industrial Res. 2013, 72, 655-662.

21. Lavi, I.; Friesem, D.; Geresh, S.; Hadar, Y.; Schwartz, B. An aqueous polysaccharide extract from the edible mushroom Pleurotus ostreatus induces anti-proliferative and pro-apoptotic effect on HT-29 colon cancer cells. Cancer Lett. 2006, 244, 61-70, https://doi.org/10.1016/j.canlet.2005.12.007.

22. Gu, Y.H.; Sivam, G. Cytotoxic effect of oyster mushroom Pleurotus ostreatus on human androgenindependent prostate cancer PC-3 cells. J. Med. Food. 2006, 9, 196-204, https://doi.org/10.1089/jmf.2006.9.196.

23. Martin, K.R.; Brophy, S.K. Commonly consumed and specialty dietary mushrooms reduce cellular proliferation in MCF-7 human breast cancer cells. Exp. Biol. Med. 2010, 235, 1306-1314, https://doi.org/10.1258/ebm.2010.010113.

24. Selegean, M.; Putz, M.V.; Rugea, T. Effect of the polysaccharide extract from the edible mushroom Pleurotus ostreatus against infectious bursal disease virus. Int. J. Mol. Sci. 2009, 10, 3616-3634, https://doi.org/10.3390/ijms10083616.

25. Kumar, H.; Bhardwaj, K.; Nepovimova, E.; Kuča, K.; Singh Dhanjal, D.; Bhardwaj, S.; Bhatia, S.K.; Verma, R.; Kumar, D. Antioxidant Functionalized Nanoparticles: A Combat against Oxidative Stress. Nanomaterials (Basel) 2020, 10, https://doi.org/10.3390/nano10071334.

26. Bhat, R.; Deshpande, R.; Ganachari, S.V.; Huh, D. S.; Venkataraman, A. Photo-irradiated biosynthesis of silver nanoparticles using edible mushroom Pleurotus florida and their antibacterial activity studies. Bioinorg Chem Appl. 2011, 2011, https://doi.org/10.1155/2011/650979.

27. Aygün, A.; Özdemir, S.; Gülcan, M.; Cellat, K.; Şen, F. Synthesis and characterization of Reishi mushroommediated green synthesis of silver nanoparticles for the biochemical applications. J Pharm Biomed Anal. 2020, 178, https://doi.org/10.1016/j.jpba.2019.112970.

28. Philip, D. Biosynthesis of $\mathrm{Au}, \mathrm{Ag}$ and $\mathrm{Au}-\mathrm{Ag}$ nanoparticles using edible mushroom extract. Spectrochim Acta A Mol Biomol Spectrosc. 2009, 73, 374-381, https://doi.org/10.1016/j.saa.2009.02.037.

29. 29. Owaid, M.N. Green synthesis of silver nanoparticles by Pleurotus (oyster mushroom) and their bioactivity: Review. Environ. Nanotechnol. Monit. Manag. 2019, 12, https://doi.org/10.1016/j.enmm.2019.100256.

30. Singh, P.; Kim, Y.J.; Zhang, D.; Yang, D.C. Biological Synthesis of Nanoparticles from Plants and Microorganisms. Trends Biotechnol. 2016, 34, 588-599, https://doi.org/10.1016/j.tibtech.2016.02.006.

31. Ribeiro, D.M.; Carvalho Júnior, A.R.; Vale de Macedo, G.H.; Chagas, V.L.; Silva, L.D.; Cutrim, B.D.; Santos, D.M.; Soares, B.L.; Zagmignan, A.; de Miranda, R.D.; de Albuquerque, P.B.; Nascimento da Silva, L.C. Polysaccharide-Based Formulations for Healing of Skin-Related Wound Infections: Lessons from Animal Models and Clinical Trials. Biomolecules 2019, 10, https://doi.org/10.3390/biom10010063.

32. Yang, J.; Han, S.; Zheng, H.; Dong, H.; Liu, J. Preparation and application of micro/nanoparticles based on natural polysaccharides. Carbohydr. Polym. 2015, 123, 53-66, https://doi.org/10.1016/j.carbpol.2015.01.029.

33. Lee, J.W.; Park, J.H.; Robinson, J.R. Bioadhesive-based dosage forms: The next generation. J. Pharm. Sci. 2000, 89, 850-866, https://doi.org/10.1002/1520-6017(200007)89:7<850::AID-JPS2>3.0.CO;2-G.

34. Jakubczyk, K.; Dec, K.; Kałduńska, J.; Kawczuga, D.; Kochman, J.; Janda, K. Reactive oxygen species sources, functions, oxidative damage. Pol Merkur Lekarski. 2020, 48, 124-127.

35. Liguori, I.; Russo, G.; Curcio, F.; Bulli, G.; Aran, L.; Della-Morte, D.; Gargiulo, G.; Testa, G.; Cacciatore, F.; Bonaduce, D.; Abete, P. Oxidative stress, aging, and diseases. Clin Interv Aging. 2018, 13, 757-772, https://doi.org/10.2147/CIA.S158513.

36. Khalil, I.; Yehye, W.A.; Etxeberria, A.E.; Alhadi, A.A.; Dezfooli, S.M.; Julkapli, N.B.M.; Basirun, W.J.; Seyfoddin, A. Nanoantioxidants: Recent Trends in Antioxidant Delivery Applications. Antioxidants 2020, 9, https://doi.org/10.3390/antiox9010024.

37. Mizuno, T. Development of an Antitumor Biological Response Modifier from Phellinus linteus (Berk. et Curt.) Teng (Aphyllophoromycetideae)-Review. Int. J. Med. Mush. 2000, 2, 21-33, https://doi.org/10.1615/IntJMedMushr.v2.i1.20. 
38. Staub, A.M. Removal of protein-Sevag method. In: Methods in Carbohydrate Chemistry. $5^{\text {th }}$ ed.; Whistler, R.L.; Bemiller, J.N.; Wolfrom, M.L.; Eds.; Academic Press, New York, NY, USA, Volume 5, 1965; pp. 5-6, https://doi.org/10.1002/ange.19650770520.

39. Yemm, E.W.; Wills, A.J. The estimation of carbohydrate in plant extract by anthrone. Biochem. J. 1954, 57, 508-514, https://doi.org/10.1042/bj0570508.

40. Lowry, O.H.; Rosebrough, N.J.; Farr, A.L.; Randall, R.J. Protein measurement with the Folin phenol reagent. J.Biol. Chem. 1951, 193 , 265-75.

41. Prieto, P.; Pineda, M.; Aguilar, M. Spectrophotometric quantitation of antioxidant capacity through the formation of a phosphomolybdenum complex: specific application to the determination of vitamin E. Anal. Biochem. 1999, 269, 337-341, https://doi.org/10.1006/abio.1999.4019.

42. Aquino, R.; Morelli, S.; Lauro, M.R.; Abdo, S.; Saija, A.; Tomaino A. Phenolic constituents and antioxidant activity of an extract of Anthurium versicolor leaves. J Nat. Prod. 2001, 64, 1019-1023, https://doi.org/10.1021/np0101245.

43. Andriy, S.; Kateřina, M.; Alla, S.; Ivan, J.; Jiří, S.; Vladimír, E.; Eliška, K.; Jana, C. Glucans from fruit bodies of cultivated mushrooms Pleurotus ostreatus and Pleurotus eryngii: Structure and potential prebiotic activity. Carbohydr. Polym. 2009, 76, 548-556, https://doi.org/10.1016/j.carbpol.2008.11.021.

44. Saranya, S.; Khanok, R.; Natta, L.; Louis, C.; Shui-Tein, C.; Patthra, P.; Chakrit, T.; Khin, K. Improved Purity and Immunostimulatory Activity of $\beta-(1 \rightarrow 3)(1 \rightarrow 6)$-Glucan from Pleurotus sajor-caju Using Cell Wall-Degrading Enzymes. J. Agric. Food Chem. 2012, 60, 5423-5430, https://doi.org/10.1021/jf300354x.

45. Shivaraj, N.; Vandana, R.; Singh, D.; Hiremath, J.; Ashish Kumar,; Mathew, J.; Haq, M. Growth Kinetics and Mechanistic Action of Reactive Oxygen Species Released by Silver Nanoparticles from Aspergillus niger on Escherichia coli. BioMed. Research International 2014, 2, https://doi.org/10.1155/2014/753419.

46. Kaviya, S.; Santhanalakshmi, J.; Balasubramanian, V. Green Synthesis of Silver Nanoparticles Using Polyalthia longifolia Leaf Extract along with D-Sorbitol: Study of Antibacterial Activity. J. Nanotechnol. 2011, 2011, https://doi.org/10.1155/2011/152970.

47. Liu, F.; Ooi, V.E.C.; Chang, S.T. Free radical scavenging activities of mushroom polysaccharide extracts. Life Sci. 1997, 60, 763-771, https://doi.org/10.1016/s0024-3205(97)00004-0.

48. Verma, A.K. Anti-oxidant activities of biopolymeric nanoparticles: Boon or bane! J. Pharm.Res. 2014, 8, 871-876. 